\title{
La enseñanza del vocabulario: la semántica idiomática en el aula
}

\author{
Nicolás Armenio JORGE RODRÍGUEZ \\ Investigador colaborador del Instituto Universitario de Lingüística Andrés Bello \\ najorger@hotmail.com
}

Recibido: mayo 2010

Aceptado: marzo 2011

\section{RESUMEN}

En el terreno de la semántica, la familia de palabras se presenta como el método más adecuado para abordar el estudio del léxico de una lengua. Por ello, proponemos la introducción de esta metodología en los distintos niveles educativos a través de ejercicios prácticos graduados según los contenidos que exige la legislación.

Palabras clave: adquisición del vocabulario, significado, semántica, familia de palabras.

\section{Vocabulary teaching: Idiom Semantics in the classroom}

\begin{abstract}
Within the field of semantics, word family is the best method to raise the study of vocabulary in a language. For this reason, this methodology is proposed in the different educational levels with some practical exercises that we adjust according to the contents of Spanish legislation.
\end{abstract}

Keywords: vocabulary acquisition, meaning, semantics, word family.

L'enseignement du vocabulaire : la sémantique idiomatique à l'école

\section{RÉSUMÉ}

Dans le domaine de la sémantique, la famille de mots est la meilleure méthode pour aborder l'étude du lexique dans une langue. Pour cette raison, on propose l'introduction de cette méthodologie dans les différents niveaux éducatifs. On inclut quelques exercices pratiques que l'on adapte par rapport aux contenus de la législation espagnole.

Mots-clés : acquisition du vocabulaire, signification, sémantique, famille de mots.

SUMARIO: 1. Introducción. 2. Educación Infantil. 3. Educación Primaria. 4. Enseñanza Secundaria Obligatoria. 5. Bachillerato. 6. Conclusiones. Referencias bibliográficas.

\section{INTRODUCCIÓN}

Si el papel de la enseñanza de la lengua es ampliar y consolidar las competencias comunicativas del alumno, el profesorado debe sopesar el rendimiento de cada uno de los métodos que se practican actualmente en el terreno de la lingüística. Si nos 
centramos en el léxico del español, el análisis del vocabulario se ha solido hacer fundamentalmente bajo tres perspectivas distintas: la perspectiva de la lexicografía tradicional, la perspectiva de los campos semánticos y, por último, la perspectiva de la familia de palabras. Son tres formas distintas de comprender el léxico de una lengua, es decir, tres formas de entender qué es el significado.

En primer lugar, la lexicografía tradicional considera que el vocabulario de una lengua solo está formado por aquellas palabras que tienen un significado conceptual, es decir, solo forman parte del léxico las palabras que señalan una realidad determinada. Además, esas palabras tendrían tantos significados como referentes, confundiéndose de esta forma el verdadero significado idiomático con la realidad extralingüística. Esta concepción referencialista es la que se utiliza en los diccionarios al uso. No se contemplan los constituyentes intrínsecos que originan las palabras, sino que se ordenan las voces de forma alfabética, describiendo única y exclusivamente las variantes según el punto de vista subjetivo del investigador, ya que incluye un número arbitrario de acepciones en un orden aleatorio ${ }^{1}$. Así, una voz como seguir tiene quince acepciones en el DRAE y diecisiete en el Diccionario Salamanca de la lengua española, reduciéndose mucho más esta información en los diccionarios académicos o escolares.

Si partimos de este análisis, como bien han expuesto algunos autores ${ }^{2}$, las lenguas naturales estarían formadas por palabras fundamentales que se organizan en un diccionario y por una gramática que actúa como instrumento de enlace entre las palabras fundamentales. No es cierto que en las lenguas haya palabras llenas o léxicas y palabras vacías o instrumentales, puesto que las lenguas no son meras nomenclaturas.

Nos podríamos preguntar, entonces, si un alumno sabe en realidad el significado del verbo seguir después de buscarlo en el diccionario. Si el alumno identifica la acepción con el significado, el caudal léxico de una lengua es inabarcable, ya que tendríamos quince seguir, sesenta y cuatro pasar, cincuenta y ocho hacer, etc. Cualquier alumno es capaz de encontrar la similitud entre "la escolta sigue al rey", "el perro sigue al amo" y "la policía sigue a los ladrones", cuyas acepciones son "ir después o detrás de alguien', 'ir en compañía de alguien', y 'perseguir, acosar o molestar a alguien: ir en su busca o alcance', respectivamente.

En segundo lugar, la perspectiva de los campos semánticos, que parte de la noción de relación asociativa de Saussure, considera que las palabras se asocian por analogía del significado, conformando estructuras. Parten de una idea conceptual del significado, es decir, no tienen en cuenta el valor invariante del significado sino que agrupan las palabras por proximidad referencial, según el punto de vista del

1 Según Casares (1992: 33), debe usarse la ordenación empírica en las acepciones, colocándose en primer lugar las acepciones más utilizadas y más conocidas, luego las anticuadas, las familiares y las figuradas, para dejar en último lugar los usos dialectales o hispanoamericanos y los tecnicismos.

\footnotetext{
${ }^{2}$ Vid. Morera 1998.
} 
investigador (Trujillo, 1996:48; García Padrón, 1998:65). Por tanto, para estudiar la lengua habría que buscar los campos semánticos o léxicos basados en la analogía del significado. Tanto los asociativistas, que estudian la asociación entre las unidades en el terreno de la realidad, como los conmutativistas, que estudian las relaciones lingüísticas tal y como son dadas en la lengua, comparten unos principios comunes: primero, separan la gramática del léxico, como ocurría en la gramática tradicional; segundo, identifican el significado lingüístico con el concepto (aunque Coseriu estudia el significado como forma de contenido, no lo separa de la realidad extralingüística); y, tercero, agrupan las palabras por su proximidad conceptual.

Si partiéramos de este método para analizar la lengua, nos encontraríamos con algunos problemas: primero, hay palabras que no se podrían analizar, ya que no pertenecerían a ningún campo semántico, considerando que hay parcelas del léxico que no están estructuradas o están débilmente estructuradas; segundo, no tendríamos criterios objetivos para conformar los campos semánticos, ya que sus componentes podrían ser infinitos y sus límites serían difusos; y, tercero, nos encontraríamos con palabras que pertenecerían a campos semánticos distintos, es decir, existirían lexemas puentes o unidades poliparadigmáticas (García Padrón, 1998; Morera, 2000 - 2001; Trujillo, 1996 y 1998).

Ni la perspectiva de la lexicografía tradicional ni la perspectiva de los campos semánticos (semántica estructural) reflejan el verdadero funcionamiento de la lengua, pues no la explican en su totalidad, ni siquiera en el terreno de la variación. Ni tienen en cuenta que los significados son invariantes y se concretan en los usos contextuales, ni contemplan las palabras como hechos de parole, como textos conformados a lo largo de la historia, sino como unidades independientes y autónomas por sí mismas, lo que hace a la lengua mucho más compleja de lo que es.

Frente a estas dos perspectivas referencialistas, surge la perspectiva de la familia de palabras, que trata de solventar los problemas teóricos y prácticos que presentan los otros métodos analizados anteriormente. En 1976 Trujillo planteó una concepción inmanentista del significado y esto ha confluido en el nacimiento de la "semántica idiomática", cuyos principios fundamentales son los siguientes:

a) El significado es una intuición semántica básica que carece de referente. No podemos considerar que el significado sea la suma de todas las variaciones contextuales sino la abstracción de ellas. Esto permite al hablante comprender los infinitos matices que puede tener un significado y, además, le permite crear otros nuevos. La capacidad designativa del signo es infinita. Por lo tanto, podemos decir que el significado o hipótesis semántica (Morera, 1994) no es conceptual, es un mecanismo psicológico ubicado en la mente de todos los hablantes y compartido por todos ellos; tiene carácter inefable, por lo que solo nos podemos acercar a él por medio de una aproximación metafórica; $y$, en último lugar, es intraducible intralingüísticamente (no existen dos unidades en una lengua que signifiquen lo mismo, por lo que la sinonimia solo se produce en el terreno de la variación), interlingüísticamente (no existe relación unívoca entre palabras de distintas lenguas), y extralingüísticamente (la relación que se establece entre un significado y su referente es arbitraria). 
b) La gramática es semántica (Trujillo, 1988: 9). Las lenguas presentan dos planos, la fonología y la semántica, o como han apuntado otros autores, el plano de la expresión y el plano del contenido. Así, las unidades morfológicas, sintácticas y léxicas, de las que hablaba la gramática tradicional, pertenecen al plano del contenido, $\mathrm{y}$, por tanto, tienen contenido semántico.

c) El significado de las palabras es el resultado de un conjunto de procedimientos semántico - formales de distintos niveles (Morera, 1994): la significación primaria, la significación morfológica, la significación categorial y la significación sintáctica.
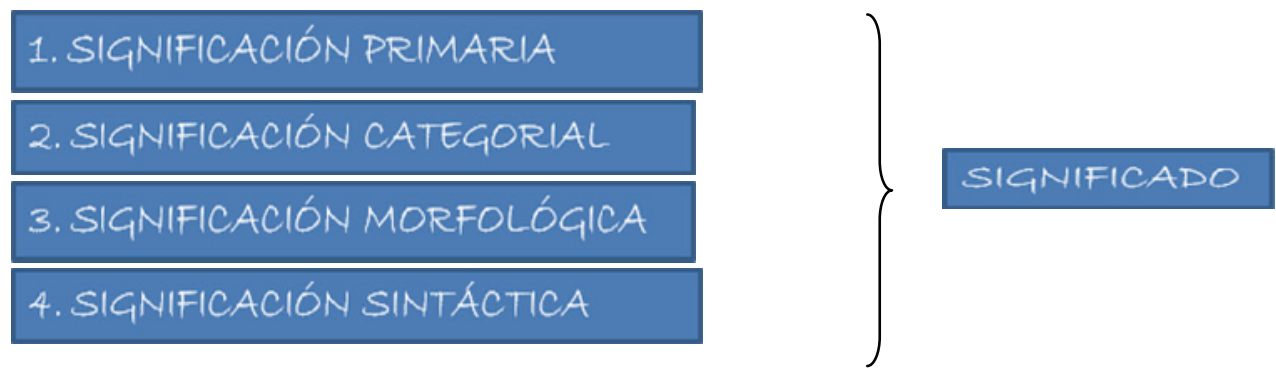

Imagen 1. Constituyentes semántico - formales de distintos niveles

La significación primaria nos facilita el conjunto de figuras de contenido estructuradas y cerradas que constituyen el significado bajo la forma del significante fonológico; la significación categorial presenta la significación primaria existiendo de tres formas en el universo del discurso (como sustantivo u objeto, como adjetivo o rasgo simple del sustantivo, o como verbo o proceso con tiempo interno); la significación morfológica amplía de forma continua y horizontal un signo con categoría mediante un signo sin categoría, dando lugar a la derivación; y la significación sintáctica amplía el signo con categoría mediante otro signo con categoría, dando lugar a la composición.

Podemos comprobarlo en la siguiente imagen donde aparece el signo "perseguido": la raíz seg- categorizada como verbo (seguir), se une al complemento sintáctico per-, formando "perseguir", y, finalmente, se une el complemento morfológico - do, constituyendo la voz "perseguido". 


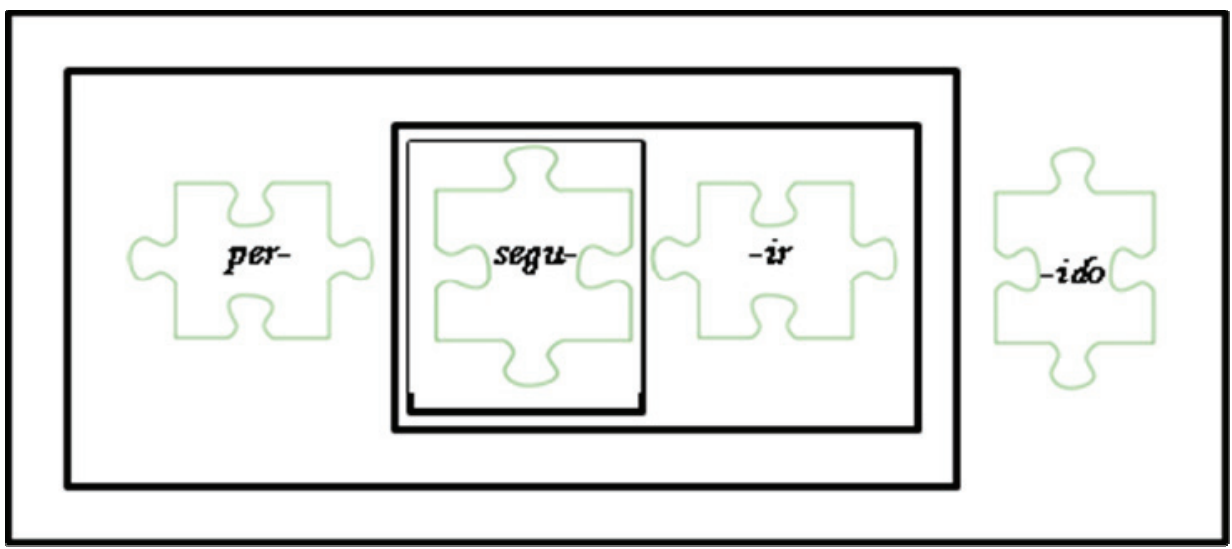

Imagen 2. Constituyentes semántico - formales de la voz perseguido

Basándose en estas ideas fundamentales, se presenta la familia de palabras como el modelo idóneo del análisis semántico inmanentista (Morer, 2007). Así, podemos definir las familias de palabras como estructuras abiertas de signos que comparten una misma significación primaria, unido a las variaciones gramaticales y denotativas de esa raíz, en definitiva, son todas las palabras que comparten un mismo lexema, ya sean palabras simples, derivadas o compuestas. De esta forma, en el análisis de una familia de palabras debemos considerar la significación invariante que comparten todas las unidades, las categorías que esa raíz ha actualizado a lo largo de la historia, las palabras derivadas, las palabras compuestas, y los campos de usos que cada una de esas unidades ha podido desarrollar.

Solo con el análisis de las familias de palabras podremos considerar, en primer lugar, que las "palabras" no son unidades autónomas sino unidades semánticamente complejas, ya que se han formado al añadir a la significación primaria uno o varios significados gramaticales (significado categorial, significado morfológico o significado sintáctico); en segundo lugar, que todos los miembros de la familia de palabras están íntimamente unidos por la significación que actúa de base de toda la familia, no por la realidad extralingüística que compartan; y, en tercer y último lugar, partiendo de este análisis podríamos explicar, a partir de la significación invariante, todas las voces presentes, pasadas y futuras, y cualquier variante diatópica, diastrática o diafásica.

El estudio de la familia de palabras es un método que nos permite dar cuenta del verdadero entramado interno de las lenguas y, por tanto, debe implantarse desde muy temprano en la educación de nuestros alumnos. Pero, ¿es posible trasladar esta teoría a los distintos niveles educativos? Sin duda, es posible implantar la semántica idiomática en nuestras aulas siempre y cuando planteemos una gradación de los contenidos según los distintos niveles educativos, y tengamos muy claro cuáles son nuestros objetivos. El alumno de Secundaria y de Bachillerato es capaz de reflexionar sobre la similitud entre seguir, secta, perseguir, secuestro, conseguir, intuyendo algunos rasgos comunes; es capaz de comprender que los sinónimos son solo 
referenciales, ya que dos palabras sinónimas no se pueden sustituir en el cien por cien de los contextos, y, por economía lingüística, no tendríamos varias unidades para un mismo significado. Son solo dos aspectos en los que el alumno puede reflexionar, ayudado por el profesor.

Sin embargo, hay muchas preguntas que tendríamos que responder previamente, así, por ejemplo, si el niño está preparado psicológicamente para recibir esta doctrina, cómo adquirimos el lenguaje desde nuestro nacimiento, si el niño solo es capaz de asociar nocionalmente las unidades, o, en definitiva, cómo estructura el vocabulario la mente humana.

Aunque hoy en día no se ha resuelto el problema de la adquisición del lenguaje, el innatismo de Chomsky sigue ganando terreno y parece mostrar un mayor número de argumentos a su favor. No podemos negar que hay predisposición biológica para la adquisición del lenguaje. Entre los dieciocho y los treinta meses el niño adquiere todas las herramientas necesarias para poder comunicarse, debido, fundamentalmente, al desarrollo cognitivo, afectivo y social y a la madurez del sistema neuronal y sensorial. Los bebés poseen cierta sensibilidad ante la comunicación humana, así, por ejemplo, son capaces de orientarse hacia el sonido, dejan de sentir miedo cuando alguien les susurra, llegando, incluso, a interpretar la entonación del habla del adulto. A pesar de que el lenguaje es extremadamente complicado, el ser humano posee las condiciones necesarias para aprehenderlo.

La predisposición genética se une también a la contextualización. Las madres (input materno) contribuyen consciente o inconscientemente en el desarrollo del lenguaje del bebé, simultaneando la comunicación verbal con la comunicación no verbal. Hay estudios que corroboran estos hechos. Por ejemplo, se ha demostrado que cuando los niños no son criados por sus madres porque se han incorporado al mundo laboral, el desarrollo léxico del niño es menor. No obstante, también hay estudios que corroboran que un niño que se educa en un centro infantil, rodeado de niños de distintas edades, desarrolla bastante su léxico. Son los adultos y, en concreto, sus propios familiares, los que estimulan la adquisición del lenguaje, sometiendo al niño a una recompensa afectiva continua. La repetición de las experiencias y la atención motivada y voluntaria del niño a determinados estímulos, conforman un hábito lingüístico, que rápidamente se almacena en la memoria lingüística. En definitiva, tanto el entorno como las características personales de cada niño contribuyen a desarrollar de forma heterogénea el lenguaje. Así, en el desarrollo del lenguaje intervienen factores individuales, factores relacionados con la atención que reciben y factores relacionados con la interacción (Bigas y Correig, 2001: 45 -ss.). Además, hay que destacar que no es una cuestión de sexo, como han apuntado algunos autores, ya que, si bien las niñas aventajan a los niños en un primer estadio, rápidamente los niños remontan el retraso en torno a los dos años y medio.

Podemos dividir la adquisición del lenguaje en dos estadios ${ }^{3}$ : un estadio prelingüístico (de 0 a 18 meses) y un estado lingüístico (a partir de los 18 meses). Las

${ }^{3}$ Cfr. Vinter (1994), Oller (1980), Oller y Lynch (1993). 
palabras no tendrán un valor representativo hasta la etapa lingüística (véase la Tabla 1), por lo que sus producciones no son más que reduplicaciones de sílabas sencillas, omisiones de vocales o consonantes, y sustituciones de fonemas complejos por otros de articulación más sencilla.

\section{Estadio prelingüistico}

\begin{tabular}{|c|c|c|c|c|}
\hline $\begin{array}{l}\text { Producción de } \\
\text { vocalizaciones } \\
\text { (0 - } 2 \text { meses })\end{array}$ & $\begin{array}{l}\text { Producción } \\
\text { de sílabas } \\
\text { arcaicas } \\
\text { (1-4 meses) }\end{array}$ & $\begin{array}{c}\text { Balbuceo } \\
\text { rudimentario } \\
\text { (3 - } 8 \text { meses) }\end{array}$ & $\begin{array}{c}\text { Balbuceo } \\
\text { canónico } \\
\text { (5 - } 10 \text { meses) }\end{array}$ & $\begin{array}{l}\text { Balbuceo } \\
\quad \text { mixto } \\
\\
(9-18 \\
\text { meses })\end{array}$ \\
\hline $\begin{array}{c}\text { Gritos } \\
\text { Bostezos } \\
\text { Suspiros } \\
\text { Arrullos } \\
\text { Fricaciones }\end{array}$ & $\begin{array}{c}\text { Sílabas } \\
\text { primitivas } \\
\text { formadas por } \\
\text { sonidos casi - } \\
\text { vocálicos y casi } \\
\text {-consonánticos }\end{array}$ & $\begin{array}{c}\text { Sonidos muy } \\
\text { agudos y sonidos } \\
\text { muy graves }\end{array}$ & $\begin{array}{c}\text { Sílabas } \\
\text { reduplicadas } \\
\text { formadas por una } \\
\text { consonante y una } \\
\text { vocal }\end{array}$ & $\begin{array}{l}\text { Primeras } \\
\text { palabras } \\
\text { reconocidas } \\
\text { como tal }\end{array}$ \\
\hline
\end{tabular}

Tabla 1. Etapas de la fase prelingüística (vid. Narbona y Chevrie - Muller, 2001)

Las primeras palabras no son abstracciones mentales de la realidad, sino que se relacionan con el objeto directamente. Son palabras aisladas que nombran estereotipos cuando el niño juega o se relaciona con los demás. De los quince a los dieciocho meses (balbuceo mixto), el niño empieza a interesarse por las cosas y empieza a generalizar las palabras aprendidas. En este momento podemos decir que comienza la etapa lingüística. Una vez que el niño ha interiorizado el significado de algunas palabras, es capaz de desligarse del contexto, ampliando la capacidad designativa de dichas unidades. Al generalizar la información de la realidad, puede nombrar objetos recurriendo a la metáfora. Se llega a un juego simbólico, en el que se pasa de lo individual a lo colectivo. Existe una estructura profunda, invariante y estable que da lugar a la estructura superficial que es variable en cada contexto de comunicación. De esta forma, el niño es capaz de prescindir de la información accidental para centrarse en las regularidades, en lo común. Memorizará las reglas deduciéndolas del uso que hagan del lenguaje los hablantes competentes que interactúan con él. Rápidamente entiende que con un número limitado de unidades puede crear un número infinito de situaciones comunicativas.

Si solo nos fijáramos en el referente, no seríamos capaces de metaforizar. Por eso, al interiorizar los rasgos fundamentales del significado de una unidad, podemos designar. Así, por ejemplo, para un niño una rosa, un clavel o un lirio, es una flor, sin necesidad de delimitar el tipo o la especie. Todos estos fenómenos van ligados al desarrollo del cerebro. Entre los dos y los tres años el niño es capaz de comprender el $99 \%$ de sustantivos, aunque solo exprese un $90 \%$; y comprende un $89 \%$ de verbos, 
expresando solo un 42,5\% (Aguado, 2000). Por ello, en los niños de dos años, la audición de cuentos se convierte en una de las técnicas más efectivas para poder desarrollar el vocabulario.

Partiendo de la idea de que el conocimiento lingüístico del niño proviene de la predisposición genética y de las deducciones del lenguaje de los adultos (familia escuela), podemos emprender el estudio del lenguaje en cada nivel educativo, proponiendo, a modo de ejemplo, algunas líneas metodológicas generales para desarrollar la lengua en los alumnos, y, en concreto, su vocabulario.

\section{EDUCACIÓN INFANTIL}

La Educación Infantil, que en España tiene carácter voluntario, está dividida en dos ciclos de tres años cada uno: el Primer ciclo de Educación Infantil ( 0 - 3 años $)$ y el Segundo ciclo de Educación Infantil (3 - 6 años). Según la legislación, durante este período educativo "se debe crear un entorno de aprendizaje abierto, a partir de un tratamiento globalizado de los contenidos, en el que el juego y el movimiento, el descubrimiento del entorno y la convivencia entre los niños y niñas y con las personas adultas cobren especial importancia y proporcionen múltiples oportunidades para aprender" (BOC 2008/203) ${ }^{4}$. Así, las enseñanzas se estructuran en tres ámbitos íntimamente relacionados: a) conocimiento de sí mismo, la autonomía personal, los afectos y las primeras relaciones sociales; b) el descubrimiento del entorno; y, por último, c) los diferentes lenguajes: comunicación y representación. Es precisamente este último ámbito el que sirve de puente entre las distintas áreas. No solo se tendrá en cuenta el lenguaje verbal, sino también el lenguaje musical, el plástico, el corporal y el audiovisual. Se aborda la comunicación desde un ámbito amplio y abarcador. A través del juego y de las rutinas diarias, el adulto debe hacer partícipes a los niños en el mundo real, ofreciéndoles una lengua que les sirva de modelo.

En el Primer Ciclo de Educación Infantil, el alumno debe comprender los enunciados emitidos por el adulto y hacer uso de todos los elementos comunicativos que estén a su alcance. Para ello el niño se iniciará en la memorización de canciones, en las representaciones de la vida cotidiana (ir al supermercado, ir al médico, jugar en el parque...) y en la audición de cuentos, por ejemplo.

En el Segundo Ciclo de Educación Infantil, el área de Lenguaje verbal se parcela en tres apartados: a) escuchar, hablar y conversar (tanto en la lengua materna como en una lengua extranjera); b) aproximación a la lengua escrita; y c) acercamiento a la literatura. Para poder expresar oralmente sus vivencias y sentimientos, y poder explicar o relatar al receptor alguna información, el alumno debe trabajar la morfología (formación de palabras), el léxico y la sintaxis (formación de oraciones).

${ }^{4}$ Por mayor cercanía y dominio, en este estudio se ha tomado como punto de partida la legislación de las Islas Canarias, que se puede consultar en la siguiente página: http://www.gobiernodecanarias.org/educacion/General/Legislacion/scripts/Claves 1.asp 
Como decía Aguado (2000: 96), “el niño que está a punto de comenzar la segunda etapa de la Educación Infantil es un ser que ya posee unos instrumentos poderosos y eficaces para categorizar la realidad, para inducir, a través de ellos, propiedades de las cosas y de los acontecimientos, para comunicarse con soltura". No olvidemos que el niño a los dos años y medio ya tiene conciencia lingüística. Así, un $75 \%$ de los sujetos de dos años y medio, estudiados por Aguado, domina las formas no personales del verbo, el presente de indicativo, el pretérito perfecto compuesto o la perífrasis aspectual con valor de futuro "ir a + infinitivo"; los artículos y los determinantes demostrativos de cercanía; los pronombres personales, demostrativos e indefinidos; los adverbios de lugar, de tiempo, de afirmación, de negación y el adverbio modal "así"; las preposiciones "a" y "en"; y la conjunción coordinada copulativa "y". Con toda esta gramática construyen oraciones simples con un pequeño grado de autocorrección.

Si centramos nuestra atención en la adquisición del vocabulario en los primeros estadios de la educación (Primer Ciclo de la Educación Infantil), el concepto de campo semántico ayuda al alumno a ampliar su caudal léxico. Así, por ejemplo, se desarrollan los campos semánticos relacionados con la familia, el cuerpo humano, los juguetes, los animales (domésticos, terrestres, aéreos o acuáticos), las comidas, las bebidas, el campo, la casa, el colegio, el tiempo (partes del día, los días de la semana, los meses y las estaciones), el mercado y las tiendas, los viajes y transportes, los oficios y algunos sustantivos abstractos. También se suelen trabajar campos semánticos adjetivales que giren en torno a los colores, las formas, los tamaños, los sabores u otros calificativos. Por una parte, el campo semántico facilita al alumno el reconocimiento de los objetos y, por otra, ayuda al niño a asociar las unidades léxicas con el contexto comunicativo, hecho que facilitará el tiempo de procesamiento de las palabras $^{5}$ (Giménez de la Peña, 2003:35). Se podría proponer como actividad práctica el uso de láminas relacionadas con un campo conceptual determinado, buscando siempre los dibujos más atractivos y los colores más llamativos, para que el esfuerzo de atención del alumno sea menor (véase la Imagen 3).

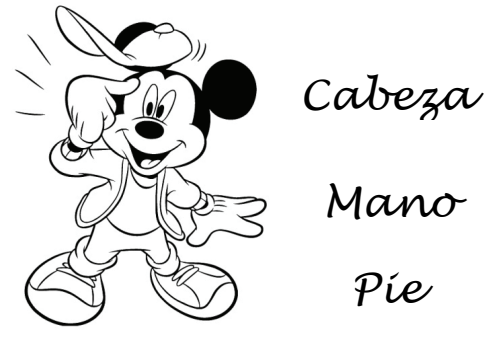

Imagen 3. Campo semántico del 'cuerpo humano'

5 De hecho, la metodología de los campos semánticos se usa cuando hay problemas lingüísticos de carencia sistemática de las estructuras del lenguaje oral (Pita y Arribas, 1991). 
En los siguientes cursos, el alumno debe ampliar esos campos semánticos, y, simultáneamente, debe trabajar la morfología, o sea, la formación de palabras. Una vez que el alumno es capaz de discriminar auditivamente el valor de los fonemas (mesa vs. pesa), y de segmentar las palabras en sílabas, hay que trabajar la formación de palabras en un nivel básico, es decir, trabajar, por ejemplo, la derivación "raíz + sufijo". De esta forma, introducimos inconscientemente el concepto de "familia de palabras". Es necesario que el alumno estructure de la mejor forma posible todo el vocabulario que aprende, y como ya hemos dicho anteriormente, los campos semánticos solo permiten ampliar la nómina de términos relacionados referencialmente, sin abordar el problema nocional. Un buen ejercicio para empezar es crear familias pequeñas que tengan un referente claro y cercano para el alumno ${ }^{6}$, como ocurre con "pan, panadero, panadería" o "carne, carnicero, carnicería". A partir de un alimento cercano al alumno, hemos formado la palabra que designa a la persona que fabrica dicho alimento (raíz +- ero), y el establecimiento en el que se vende $($ raiz +- ero $+-i a)$. ¿Cómo trabajar la morfología? Hay muchas formas de hacer atractivo el estudio de las familias de palabras. Podemos recurrir a las láminas ilustrativas (véase la Imagen 4), diapositivas, transparencias o presentaciones en el ordenador, $y$, por medio de preguntas, extraer la información adecuada del alumno (¿Cómo se llama este alimento? ¿Quién lo hace? ¿Dónde lo hace?).
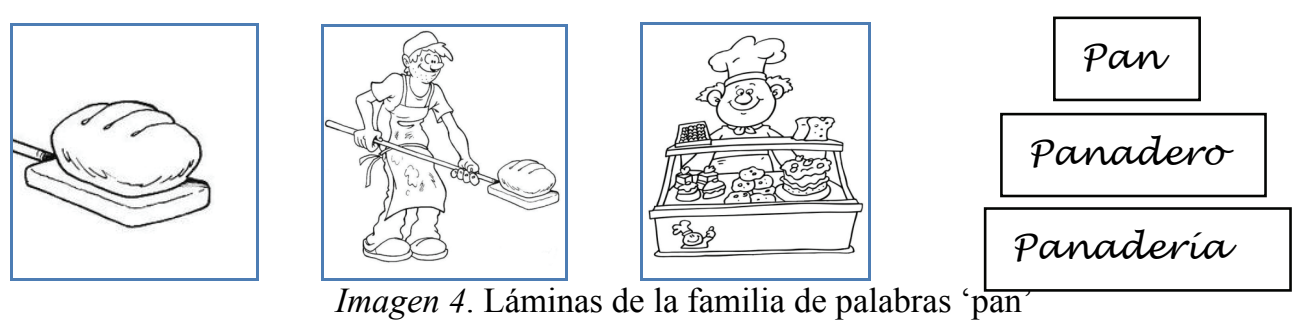

Aprovecharemos también para explicar cómo se hace el pan, con qué ingredientes, qué productos dulces o salados fabrica el panadero también, qué se puede comprar en una panadería, e incluso, si el alumno estudia en una escuela rural, preguntar por el panadero del pueblo, dónde está la panadería, cómo se llama, qué venden allí... Es un tema recurrente para la dramatización de una escena habitual en una panadería. Una vez que hemos trabajado distintas familias de palabras, relacionadas con los alimentos, podemos recrear en la clase un mercado en el que encontremos una panadería, una carnicería y una pescadería, con sus trabajadores respectivos (panadero, carnicero y pescadero). Se recrearán situaciones comunicativas reales. Por ejemplo, un niño tiene la misión de ir a la carnicería a pedirle al carnicero un kilo de carne. Se puede entablar un diálogo como el siguiente:

${ }^{6}$ El estudio de los sustantivos concretos será previo al estudio de los sustantivos abstractos, pues estos últimos son más difíciles de asimilar en este nivel educativo. 


$\begin{array}{ll}\text { Carnicero. } & \text { ¿Buenos días, don Pedro! } \\ \text { Pedro. } & \text { ¿Buenos días! } \\ \text { Carnicero. } & \text { ¿Qué quiere que le ponga hoy de mi carnicería? } \\ \text { Pedro. } & \text { Quiero un kilo de carne. } \\ \text { Carnicero. } & \text { ¿Carne de cerdo o de ternera? } \\ \text { Pedro. } & \text { Prefiero carne de cerdo. } \\ \text { Carnicero. } & \text { Pues aquí tiene. Son diez euros. } \\ \text { Pedro. } & \text { Tome el dinero. ¡Muchas gracias! } \\ \text { Carnicero. } & \text { ¡Gracias a usted! ¡Hasta la próxima! } \\ \text { Pedro. } & \text { iAdiós! }\end{array}$

De este modo, los niños han trabajado las palabras carne y carnicería en un contexto real. Además, han puesto en práctica las normas sociales del saludo y la despedida, las intenciones comunicativas, el intercambio producto - dinero y la educación ciudadana.

También se puede utilizar el cuento como soporte educativo, representándolo con marionetas $\mathrm{u}$ otros muñecos. Podemos trabajar primero la audición de cuentos que contengan las palabras estudiadas, haciendo hincapié en ellas. Por ejemplo:

Érase una vez un pequeño corderillo al que su madre le había mandado a comprar una barra de pan. Pero, ¿a dónde tenía que ir para comprar esa barra de pan? esperamos la respuesta de los alumnos-. Efectivamente, el corderillo tenía que ir a la panadería, pero como no sabía ir, le preguntó a un viejo pastor que caminaba por el campo:

- Señor, señor, ¿me puede decir dónde está la panadería? Es que mi madre me ha mandado a comprar una barra de pan, pero no sé llegar.

- Jovencito, hoy no podrás comprar el pan porque el panadero está enfermo y su panadería está cerrada, - le contestó el viejo pastor.

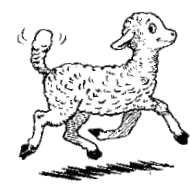

- ;Oh! Entonces hoy no puedo comer pan. Voy a decírselo a mi madre. ¡Gracias, pastor!, -respondió el corderillo.

Son pequeñas narraciones creadas según el nivel educativo que permiten al alumno memorizar, no solo las palabras trabajadas, sino que también le permiten interiorizar las reglas de formación de derivados. A la par se puede trabajar la comprensión lectora haciéndole preguntas al alumno: ¿Quién tenía que ir a comprar? ¿Qué iba a comprar el corderillo? ¿Quién lo mandó a comprar?... Y se pueden extender las preguntas, recordando otras familias de palabras o atendiendo a la curiosidad del alumno: "y si lo que quiero comprar es pescado, ¿a dónde voy? ¿Quién lo vende?". En segundo lugar, podríamos trabajar la imaginación de los niños, creando un cuento colectivo tras ofrecerles imágenes como las que presentábamos anteriormente (véase Imagen 4).

Trabajar frecuentemente las familias de palabras repercutirá en el reconocimiento de la lengua materna y de sus reglas gramaticales básicas de formación de palabras, 
que permitirán estructurar coherentemente el vocabulario y ampliar la nómina de unidades léxicas.

\section{EDUCACIÓN PRIMARIA}

La Educación Primaria, que está dividida en tres ciclos educativos de dos años cada uno (niños de 6 a 12 años), forma parte de la educación básica junto con la enseñanza secundaria obligatoria. Es un período de tiempo largo, pero muy importante en el desarrollo del niño como persona. Sus fines son la adquisición de las habilidades culturales básicas, el desarrollo personal del niño y de sus competencias comunicativas. La graduación de los contenidos es un reto para el profesorado, puesto que la competencia de un niño del primer ciclo es completamente diferente a la competencia del alumno del tercer ciclo. Durante la etapa de la enseñanza primaria aparecerá la reflexión sistemática sobre el lenguaje que ya saben utilizar. Será el profesor el encargado de dirigir la reflexión sobre este código. Sin olvidarnos de que todas las actividades creadas en el entorno escolar deben tener una función comunicativa, representativa y lúdica, tendremos en cuenta que en esta etapa se debe ahondar más en la alfabetización, ya que el niño entra en contacto más directo con la escritura.

En el currículo de la Educación Primaria nos encontramos con cuatro bloques relacionados con las habilidades lingüísticas: "escuchar, hablar y conversar", "leer y escribir", "educación literaria" y "conocimiento de la lengua". Todos están íntimamente relacionados, pero es el último bloque el que aborda con mayor precisión la reflexión lingüística, ya que implica el desarrollo de la consciencia lingüística, el uso de las formas y los mecanismos necesarios para comunicarse, recurriendo siempre al metalenguaje.

En el primer ciclo es fundamental enseñar al alumno a leer y a escribir correctamente, pues serán las dos tareas más importantes a lo largo de la enseñanza escolar. Por ello, el reconocimiento de las grafías, la segmentación en sílabas y palabras, o el conocimiento de las reglas ortográficas básicas son algunos de los contenidos fundamentales. No obstante, podemos seguir trabajando la derivación y la composición, y las categorías gramaticales. En el primer curso abordaremos los conceptos de singular - plural, masculino - femenino, la formación de diminutivos y el reconocimiento de las tres categorías gramaticales (el sustantivo, el adjetivo y el verbo). Por ejemplo, en el primer ejercicio que proponemos a continuación el alumno trabajará el reconocimiento y uso del morfema de plural $-s$, al igual que la concordancia entre determinante - sustantivo; en el segundo ejercicio, trabajará la formación de palabras, en concreto, la formación de diminutivos gracias al sufijo -ito. Aprovechando los conocimientos previos, se puede jugar con el cambio de género y de número. 

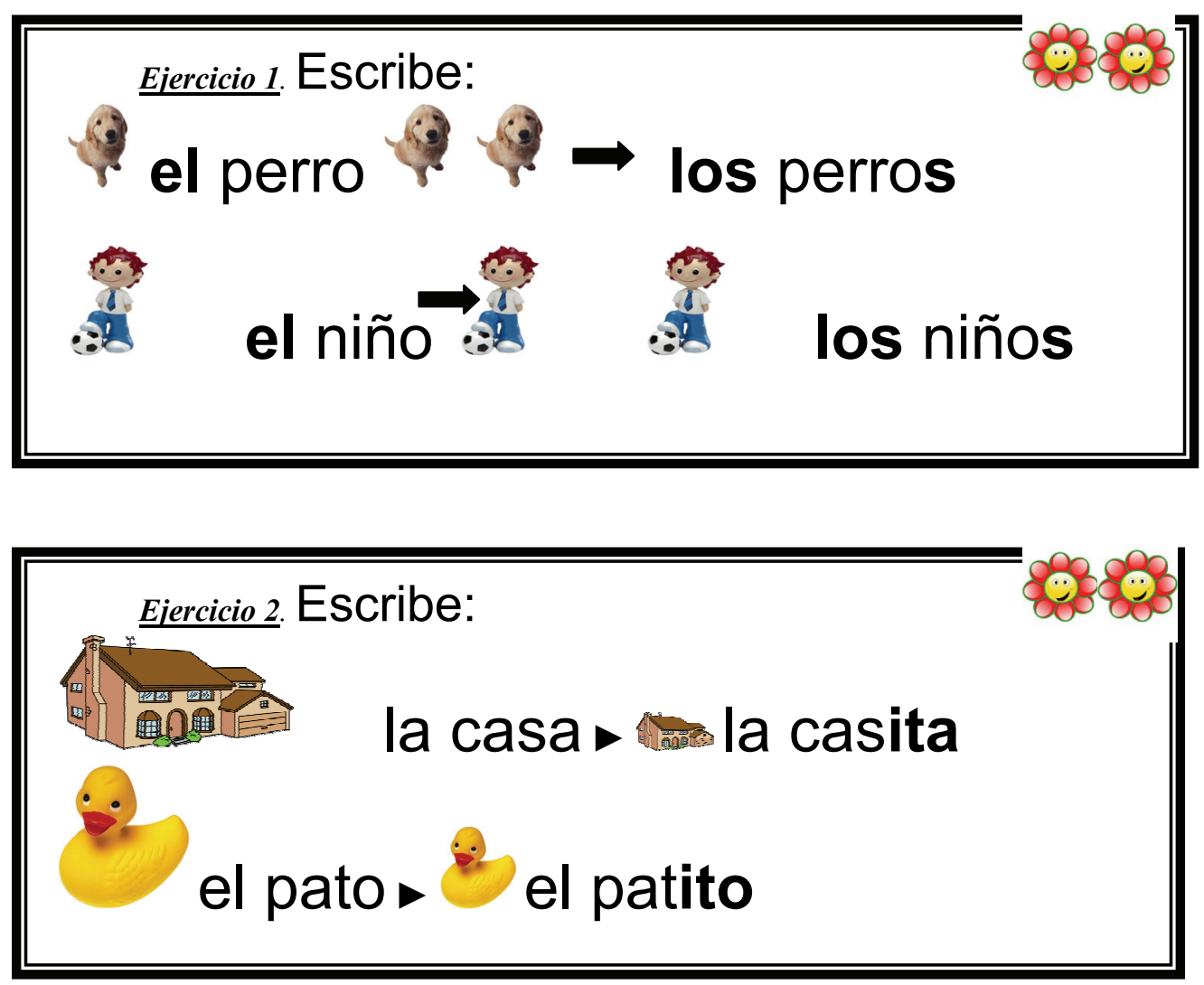

Es muy importante utilizar desde los primeros estadios educativos los términos lingüísticos con precisión para que no haya confusión en la mente del alumno. Las nociones de significado y sentido se confunden en este nivel, por lo que hay que explicar al alumno que el significado es el contenido semántico del signo, de las palabras, difícil de describir si no se hace un estudio profundo de las voces. Por ello, normalmente recurrimos a los sentidos que ha generado ese significado, es decir, a las acepciones o usos contextualizados, que son los que encontramos en el diccionario escolar.

Si trabajamos gradualmente estos conceptos, el alumno estará preparado para construir las familias de palabras. Los campos semánticos o los campos léxicos solo nos servirán ahora para trabajar las categorías gramaticales, pero no para estructurar el vocabulario ni para invertir el déficit léxico ( $c f r$. Ortega, 1996). El alumno puede crear el campo semántico de la escuela o de las partes del cuerpo, pero solo estaremos elaborando una nomenclatura de términos, muy útil para trabajar la noción de sustantivo, por ejemplo. De la misma forma podemos crear el campo léxico de la escuela, bien practicando solo los sustantivos (objetos y personas que encontramos en 
un colegio), o practicando todas las categorías gramaticales (sustantivos, adjetivos y verbos relacionados con la escuela).

Ante un ejercicio como el que proponemos a continuación (véase el Ejercicio 3), muy reproducido en los libros de textos escolares, el alumno creará una nómina heterogénea de unidades, $\mathrm{y}$, según sea el núcleo del campo semántico, los alumnos incluirán más o menos voces.

Ejercicio 3. Vas a escribir todas las palabras que tú creas que están relacionado. on el campo. Hay muchas, ; a ver cuántas puedes decir!

\section{El campo}

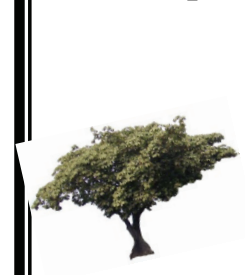

Un alumno de un colegio rural podrá escribir palabras como azada, tractor, sacho, rastrillo, manguera, pala, cesta, surco, alimentos que se produzcan en esas localidades... Frente a esto, un alumno de ciudad solo será capaz de mencionar hiperónimos como flor, fruta, verdura o animales, sin apenas precisión. ¿A qué se debe este fenómeno? Pues es muy sencillo, la realidad extralingüística está influyendo en la elección de las unidades. Esto no quiere decir que un habitante de ciudad no conozca las herramientas de la huerta, sino que no siente la cercanía conceptual porque no ve esas herramientas a diario. Esto demuestra que el léxico no se puede organizar en campos semánticos, en campos conceptuales, puesto que estos campos variarían según el sujeto que los estructure. La lengua está estructurada en familias de palabras, en palabras que se relacionan intralingüísticamente.

En los dos ciclos siguientes continuaremos con estas teorías graduando los contenidos según los objetivos que debemos conseguir. El alumno debe entender que la significación común solo se comparte cuando las unidades se crean a partir de una misma raíz. Los objetos pueden estar relacionados por su proximidad en la realidad, por su proximidad conceptual, pero esto no quiere decir que compartan un mismo significado. Ante un ejercicio como el siguiente (Ejercicio 4), en el que se mezclan los conceptos del campos semántico de la "escuela" y de la familia de palabras "libro", el alumno tendrá que darse cuenta de que solo se pueden seleccionar las voces que parten de la raíz libr-, observando que en todas ellas se repite un mismo significado que se formaliza bajo un único significante. No solo trabajamos la significación, sino también la búsqueda de las raíces y de los morfemas (prefijos y sufijos). Se buscan las similitudes entre las voces destacando lo que comparten, su significado y su raíz. Para obtener el máximo rendimiento, el profesor será el encargado de guiar la reflexión: si profesor está relacionado con libro, ya que el 
profesor usa el libro en su trabajo, ¿cuál es el significado común? Por otra parte, ¿en las definiciones de librero estaría incluida la de libro? ¿y en la de librería? Entonces, ¿en torno a qué idea, a qué significado giran todas las palabras que comparten la raíz libr-?.

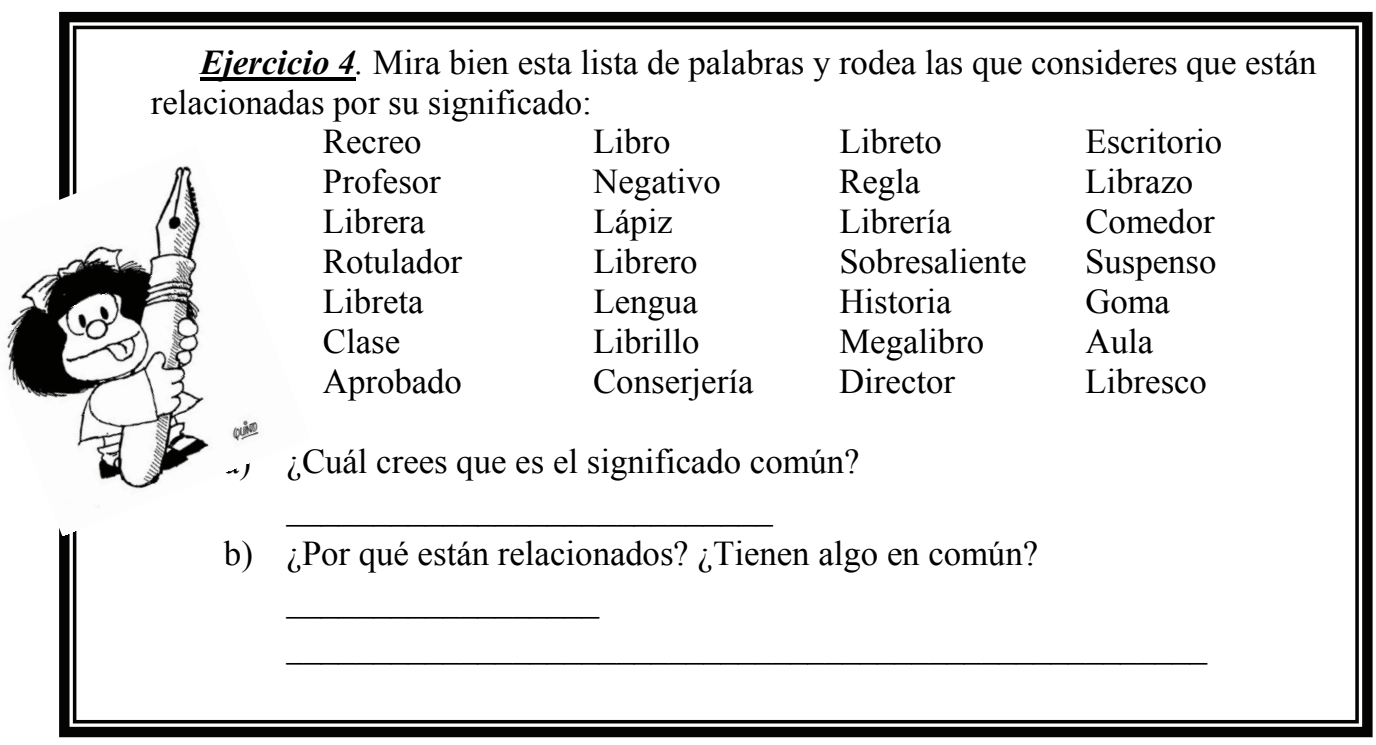

Ha llegado la hora de explicar el verdadero valor de las palabras. Las palabras son textos, son mecanismos que se han ido conformando a lo largo de la historia gracias al consenso entre los hablantes. Todas las palabras son monosémicas ${ }^{7}$, es decir, en las lenguas siempre se establece una relación unívoca entre un significante y un significado. Este planteamiento teórico conlleva una revisión de los principales tecnicismos. Así, por ejemplo, habrá que explicar la inexistencia de la sinonimia o de la polisemia tal y como se ha venido explicando hasta la actualidad, pues una palabra solo tiene un único significado que podrá generar infinitos usos contextuales o sentidos. El alumno, por sí mismo y ayudado por el profesor, podrá interiorizar esta teoría. Si le presentamos un par de oraciones como en los ejemplos 1 y 2, es posible que el alumno de primaria no encuentre el matiz que diferencia los dos adjetivos, pues no reparará en sus raíces, ya que su dominio lingüístico no se lo permite. Sin

${ }^{7}$ Para comprender esta hipótesis hay que delimitar las nociones de significado y sentido o acepción. De hecho, hay algunos autores (Alvar Ezquerra, 2003) que mantienen la confusión entre estos dos términos, pues a pesar de que consideran que el significado de las palabras es único y que "lo que varían son los sentidos que se toma, y las acepciones que se van consolidando en la lengua" (Alvar Ezquerra, 2003: 52), luego afirma que la monosemia es rara en las lenguas. 
embargo, si le ofrecemos dos oraciones como los ejemplos 3 y 4 , se dará cuenta de que, si consideramos que dos palabras son sinónimas porque comparten el mismo significado, y el verbo dar y producir se consideran sinónimos, algo falla en la teoría, pues no es posible la construcción producir + clases.

1) Juan aprueba todos los exámenes, es muy listo.

2) Juan aprueba todos los exámenes, es muy inteligente.

3) El profesor $d a$ las clases

4) *El profesor produce las clases

El árbol da fruto o produce fruto, pero el profesor no puede producir sus clases. Este sería un buen ejercicio para delimitar el alcance de los sinónimos. De la misma forma, palabras que tradicionalmente se han considerado "polisémicas" como diente, cabeza, antena, banco o caracol no tienen varios significados, sino varias acepciones, por lo que el tecnicismo lingüístico, es decir, el término "polisemia", no es apropiado.

Dentro de la morfología, en el terreno de la formación de palabras, ofreceremos al alumno el siguiente esquema (Imagen 5):

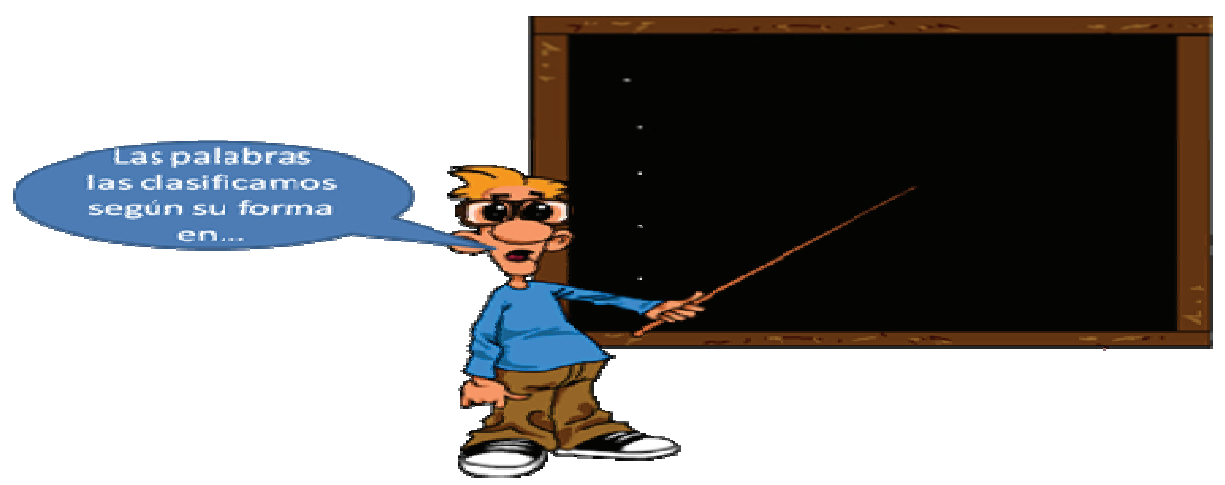

Imagen 5. Clasificación de las palabras según su forma

Una vez estudiada la diferencia entre lexema y morfema, abordaremos los conceptos de palabras simples (palabras formadas por un solo lexema o raíz), palabras derivadas (palabras formadas por un lexema y uno o varios morfemas - prefijos, sufijos o interfijos), palabras compuestas (palabras formadas por varios lexemas), siglas (palabras que se han formado al unir las letras iniciales de una secuencia mayor de palabras), y acortamientos o abreviaturas (palabras formadas tras la elisión de la parte final de su lexema y de sus morfemas). 


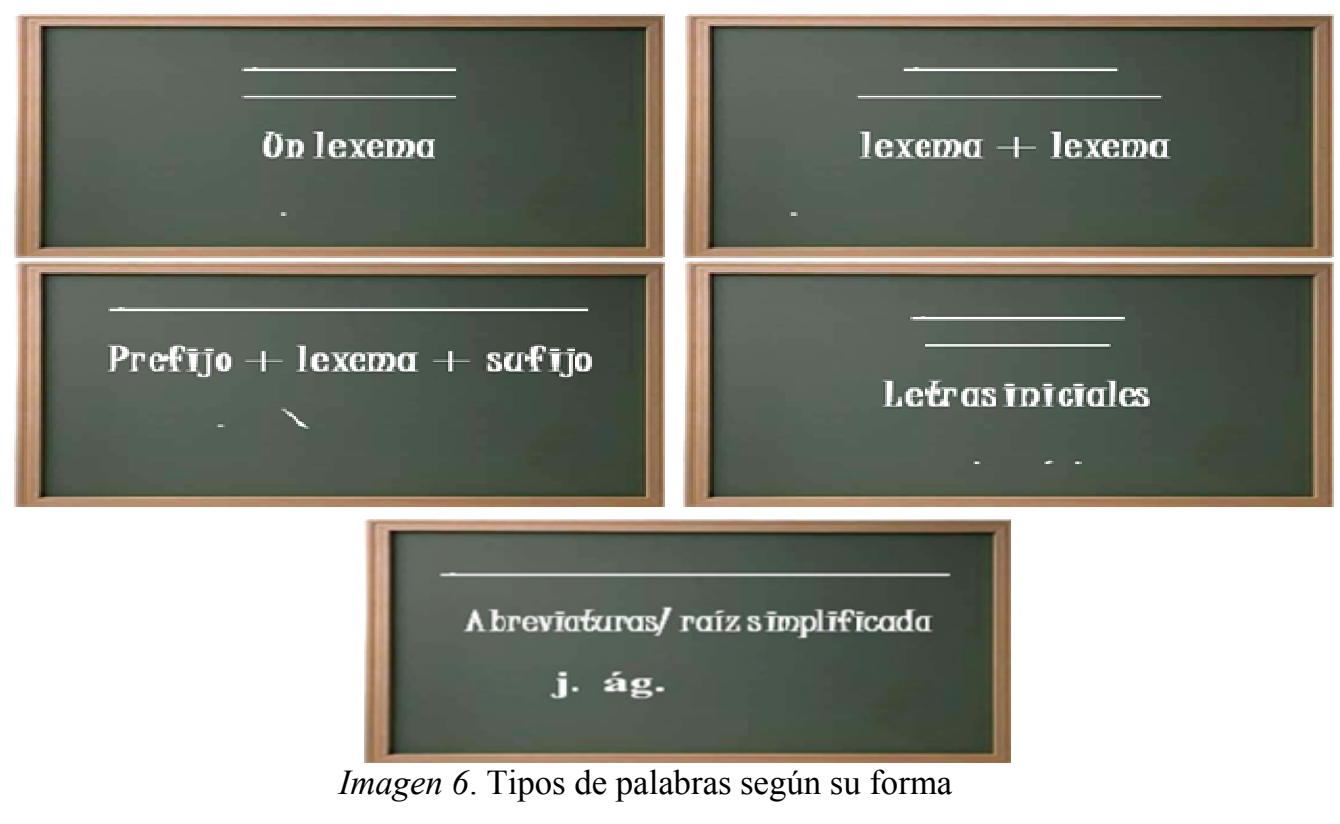

No obstante, haremos hincapié en los mecanismos de formación de palabras más relevantes: la derivación y la composición. Se trabajará la formación de diminutivos (-ito, -ita, -illo, -illa), de aumentativos (-ón, -ona, -azo, -aza, -ote, -ota), de despectivos (-ucho, -ucha, -aco, -aca), de gentilicios (-ero, -eño, -és), el uso de prefijos que denoten negación (por ejemplo, in- o des-), de prefijos que denoten lugar (por ejemplo, sub- o inter-), así como los sufijos que provocan un cambio en la categoría gramatical de la palabra base (por ejemplo, con el sufijo -ción formamos sustantivos a partir de verbos, frente al sufijo - oso con el que formamos adjetivos de sustantivos). Con los ejercicios conseguiremos que el alumno delimite los morfemas (sufijos, prefijos o interfijos), segmente las voces en sus constituyentes mínimos, construya nuevas voces y aprenda alguno de los valores - usos contextuales de dichos morfemas.

Con estos conocimientos y el dominio de las categorías gramaticales se podrá emprender el estudio de las familias de palabras de forma más precisa. Por ejemplo, individualmente el alumno escribirá derivados y compuestos de algunas palabras simples. Una vez concluyan el ejercicio, se hará una puesta en común para ampliar la familia de palabras con el resto de las unidades que ha formado toda la clase (Ejercicio 5). También se puede trabajar la delimitación de la raíz comparando las similitudes entre los miembros que conforman una familia, eliminar los intrusos dentro una familia, o aproximarnos a la significación de la raíz y a sus principales sentidos (véase, v. gr., el Ejercicio 6). 
Ejercicio 5. Completa la siguiente tabla:

\begin{tabular}{|c|c|c|}
\hline Palabras simples & Palabras derivadas & Palabras compuestas \\
\hline Papel & (papelera) & (pisapapeles) \\
\hline Limpiar & (limpieza) & (limpiabotas) \\
\hline Punta & (puntilla) & (sacapuntas) \\
\hline Cara & (carota) & (caradura) \\
\hline
\end{tabular}

Ejercicio 6. Completa estas oraciones con palabras de la misma familia:

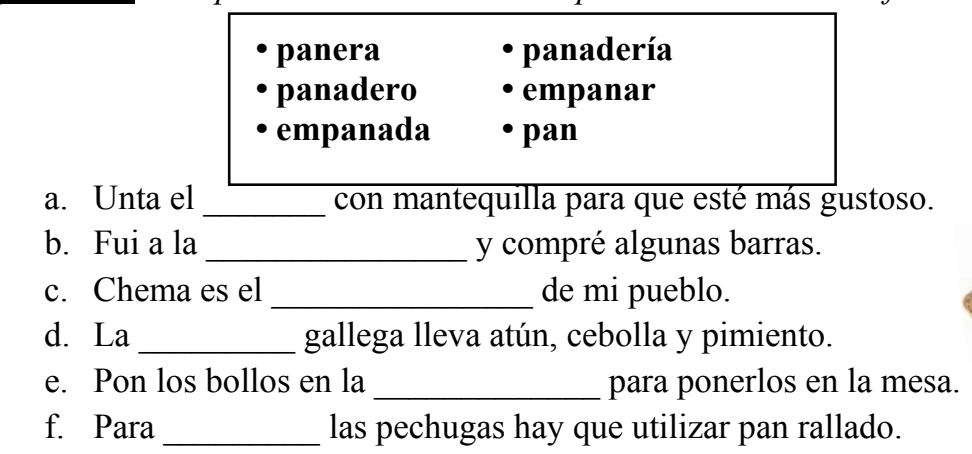

Junto a estos presupuestos, el diccionario seguirá siendo una herramienta de consulta obligatoria en los distintos niveles educativos, siempre y cuando se considere una obra cultural, la recopilación de las variantes contextuales de las voces de una lengua. Se debe enseñar al alumno cuáles son las características de cada diccionario y aclarar lo que vamos a encontrar en ellos (Alvar Ezquerra, 2003: 12 - ss.). Por ejemplo, podemos explicar que en un diccionario al uso no encontraremos significados sino los usos contextuales de esas unidades; en un diccionario de sinónimos y antónimos encontraremos voces que alternan o contrastan en determinados contextos; en uno etimológico encontraremos las palabras que están relacionadas formalmente por la misma raíz y que tienen un origen histórico común; en los diccionarios ideológicos encontraremos las unidades que se relacionan conceptualmente; en los dialectales encontraremos las "señas de identidad cultural" de cada parcela geográfica (Ortega, 1996: 215 - 217), y así, sucesivamente.

\section{ENSEÑANZA SECUNDARIA OBLIGATORIA}

Los dos ciclos de dos cursos cada uno que conforman la Educación Secundaria Obligatoria (alumnos de 12 a 16 años), finalizan la educación básica del alumno, 
posibilitando su entrada en el Bachillerato, en los ciclos formativos o, incluso, en el mundo laboral. En cualquier supuesto, la competencia lingüística de este nivel debe permitir la comprensión y la expresión adecuada.

A la hora de enseñar el vocabulario debemos seguir teniendo en cuenta su pronunciación y su ortografía, su significado, el uso gramatical de las voces, los mecanismos formales que la han constituido como palabra (derivación, composición o acortamiento), las restricciones de uso, su variación contextual (variación diatópica, diastrática o diafásica), y las posibles relaciones semánticas que se establezcan con otras palabras (familia de palabras). Aunque la palabra es la unidad mínima de comunicación, no podemos olvidarnos de que es un texto complejo que se ha formado al unir uno o varios lexemas con uno o varios morfemas. De esta forma el significado de una palabra es la suma de los distintos significados de cada uno de sus constituyentes.

¿En qué cambian las clases de lengua con respecto a los cursos precedentes? Lo único que cambia es el grado de dificultad de los distintos contenidos. Las nociones de coherencia y cohesión que se exigen al alumno deben sustentarse en el dominio de los mecanismos de formación de palabras. Aunque en este nivel educativo prima la funcionalidad de las unidades, no podemos descuidar la significación invariante de estas, que proporcionará al alumno un dominio mayor de la lengua. Para ello podríamos proponer ejercicios donde el alumno tenga que buscar las palabras que se relacionan según su significado, por ejemplo, con el verbo "seguir" (Ejercicio 7). Aunque las veinte palabras que se citan en este ejercicio forman parte de la familia de palabras 'seg-' (y su variante formal sec-), lo más probable es que el alumno no marque alguna de ellas, como "secta" o "secuestro". A continuación se abrirían dos nuevos apartados en el ejercicio: en primer lugar se deberá rastrear la evolución de la raíz utilizando los diccionarios etimológicos; en segundo lugar, habrá que buscar la relación que hay entre seguir - secta, o seguir - secuestro. Analizando detenidamente el significado de la raíz ('movimiento orientado y subordinado'), se podrá demostrar que en una secta los miembros siguen a un líder, y en un secuestro, el secuestrado sigue al secuestrador. 
Ejercicio 7. ¿Qué palabras están relacionas con "seguir”? Rodea la respuesta correcta
1. Seguir
Sí / No 11. Séquito
Sí / No
2. Perseguir
Sí / No 12. Segundón
Sí / No
3. Secta
Sí / No 13. Secundario
Sí / No
4. Conseguir
Sí / No 14. Seguimiento
Sí / No
5. Seguidamente
Sí / No 15. Consecutivo
Sí / No
6. Seguidilla
Sí / No 16. Obsequio
Sí / No
7. Seguido
Sí / No 17. Proseguir
Sí / No
8. Segundo
Sí / No 18. Persecución
Sí / No
9. Según
Sí / No 19. Seguíamos
Sí / No
10. Seguidor
Sí / No 20. Secuestro
Sí / No

¿Tienen algo en común todas las palabras que están relacionadas con "seguir”?

¿Qué se repite en todas las palabras?

Unidades como secta o secuestro son bastante recurrentes entre los adolescentes para ampliar la competencia cultural: ¿qué es una secta? ¿Cuántos tipos de sectas hay? ¿Las religiones son sectas? ¿Qué provoca que voces como estas tengan connotaciones negativas, su significado o su uso? ¿Cuándo surgen estas voces? Las respuestas a estas preguntas ayudan a entender el significado $\mathrm{y}$, sobre todo, demuestran que aunque cambien las acepciones a lo largo de la historia, su significado permanece inalterable. Así, por ejemplo, podríamos empezar diciendo que la voz secta se usaba en latín para referirse a un grupo de personas que seguía unos determinados ideales, es decir, una especie de escuela. Una vez que el cristianismo se consolida como religión oficial del Imperio con Teodosio I en el 380 d. C., la Iglesia rechaza estos grupos minoritarios, considerándolos movimientos sectarios. El Imperio considera herejes a todos los miembros de las sectas. Pero hoy en día las connotaciones de secta son mucho más negativas, ¿por qué? Esto se debe, sencillamente, a los acontecimientos históricos en los que se ha visto envuelta la voz: las muertes misteriosas de muchos miembros de sectas (Secta El templo del Pueblo en 1978, la secta de David Koresh en 1993, la secta Templo Solar en 1994, o la secta de la Madre Aida en Tenerife en 1998, entre otras), y la condición de súbditos de éstos infiere peligrosidad a estos movimientos. Sin embargo, tanto la secta romana como las sectas satánicas actuales siguen manteniendo el mismo significado de la raíz que actúa de base: hay un movimiento orientado y subordinado, en este caso con respecto al líder.

Siguiendo con el estudio de esta familia de palabras podríamos proponer a los alumnos que buscaran titulares de noticias que contengan palabras que pertenezcan a 
esta familia (Ejercicio 8). A continuación, explicarán por qué pertenecen a esa familia, cómo se han formado, cuál es su posible significado con respecto a la raíz, y cuáles son sus usos.

Ejercicio 8. Busca titulares en el periódico que contengan palabras que formen parte de la familia "seguir":

Estos podrían ser algunos titulares:

a) "Funcionarios de Madrid denuncian acoso por negarse a seguir a políticos", El Pais, 27/01/2009.

b) "El supremo prosigue hoy sus intensos debates sobre Ciudadanía", El País, 27/01/2009.

c) "Bruselas vaticina dos años seguidos de recesión en España", El País, 20/01/2009.

d) "Alemania aprueba un segundo plan ante la dureza de la crisis", El País, $14 / 01 / 2009$.

e) "38 días bajo el Kalásshnikov", José Cendón y Colin Freman relatan su cautiverio en Somalia: quiénes les secuestraron, las amenazas de muerte y los juegos con los piratas, El País, 11/01/2009.

Según el nivel alcanzado por los alumnos, hay que empezar a esquematizar los principales sentidos contextuales de los prefijos y sufijos, lo que permitirá abordar a continuación la significación de los morfemas (véase la Imagen 7 y la Imagen 8).

\begin{tabular}{|c|c|l|}
\hline SUFIJO & ACEPCIÓN & EJEMPLO \\
\hline- isimo & 'superlativo' & Altísimo \\
\hline- mento,,- miento & 'abstractos verbales' & Sentimiento \\
\hline- torio & 'lugar' & Laboratorio \\
\hline- dor, $-a /$-tor,,$-a$ & 'oficio, relación o referencia' & Pastor \\
\hline$-d a d /-$ tad & 'cualidad' & Amabilidad \\
\hline$-b i l /-b l e$ & 'posibilidad' & Creíble \\
\hline$-a l /-a r$ & 'conjunto de' & Pin $\underline{\underline{a r}}$ \\
\hline
\end{tabular}

Imagen 7. Cuadro de las principales orientaciones de sentido de algunos sufijos 


\begin{tabular}{|c|c|l|}
\hline PREFIJO & ACEPCIÓN & EJEMPLO \\
\hline Co- $/$ com-/con- & 'compañía, unión' & $\underline{\text { Composición }}$ \\
\hline$I n-/ i-$ & 'negación, privación' & $\underline{\text { legal }}$ \\
\hline Per- & 'a través de' & $\underline{\text { Perseguir }}$ \\
\hline Post $-/$ pos- & 'después de' & $\underline{\text { Pospuesto }}$ \\
\hline$R e-$ & 'volver a , repetir' & $\underline{\text { Reescribir }}$ \\
\hline$E x-$ & 'fuera de' & $\underline{E x t r a e r}$ \\
\hline
\end{tabular}

Imagen 8. Cuadro de las principales orientaciones de sentido de algunos prefijos

Hay dos formas de completar estas tablas: o bien el alumno copia literalmente lo que dice el profesor, que se ayudará de numerosas obras que existen en el mercado sobre la formación de palabras (por ejemplo, Varela Ortega, 2005; Morera, 2005); o bien, es el propio alumno el que trata de delimitar primero el morfema y, luego, deduce un posible sentido, comparando voces que comparten el mismo morfema. Obviamente, el segundo método es más productivo ya que será el alumno el que rastree los entresijos lingüísticos por sí mismo, aunque siempre guiado por el profesor. Para ello, se puede proponer al alumno completar tablas como las que aparece en el Ejercicio 9, en la que el alumno, primero tendrá que rastrear si existe o no el prefijo unido a la raíz y, en segundo lugar, tendrá que ver cuál es el matiz que aporta, por ejemplo, el prefijo "com-" en las combinaciones componer y comportar.

\begin{tabular}{|c|c|c|}
\hline \multicolumn{3}{|c|}{ Ejercicio 9. Escribe en la casilla el verbo si existe unido al prefijo: } \\
\hline Prefijos & Poner & Portar \\
\hline$a-$ & (*aponer) & (aportar) \\
\hline Ante- & (anteponer) & - \\
\hline Com-/con- & (componer) & (comportar) \\
\hline Contra- & (contraponer) & - \\
\hline$D e-$ & (deponer) & (deportar) \\
\hline Di-/des-/dis- & (disponer) & - \\
\hline Em-/en-/in-/im- & (imponer) & (importar) \\
\hline$E x-/ e-$ & (exponer) & (exportar) \\
\hline Inter-lentre- & (interponer) & - \\
\hline$O b-/ o-$ & (oponer) & - \\
\hline Post-/pos- & (posponer) & - \\
\hline Pre- & (*preponer) & - \\
\hline Pro- & (proponer) & - \\
\hline$R e-$ & (reponer) & (reportar) \\
\hline $\mathrm{Su}-/ s o-/ s u b-/ s u s-$ & (suponer) & (soportar) \\
\hline Super-/sobre- & (sobreponer) & - \\
\hline Trans- / tras- & (trasponer) & (transportar) \\
\hline
\end{tabular}


También podríamos explicar la alomorfía de los prefijos (com-/con-) o de las raíces (lech- / láct-), e incluso el problema de la actualización de las voces (aunque los verbos *aponer y *preponer no se han actualizado en español como palabras independientes, sí es cierto que hay voces que derivan de ellos, como *aponer > aposición $\mathrm{o}$ *preponer $>$ preposición).

Además debe estudiarse la composición con lexemas grecolatinos: carn- ('carne'), api- ('abejas'), homi- ('hombre'), multi- ('mucho'), igni- ('fuego'), hervi- ('hierba'), audi- ('oír'), -voro ('que come'), -fero ('que lleva o produce'), etc. De esta forma, se explicarán compuestos como carnivoro ('que come carne'), homicida ('que mata a personas'), o multiforme ('de muchas formas').

\section{BACHILLERATO}

El Bachillerato es una enseñanza opcional en España, por lo que los alumnos que lo cursan, en sus distintas modalidades, tratan de profundizar en los contenidos conseguidos en la ESO. Como establece el Decreto 202/2008 de 30 de septiembre, la finalidad del Bachillerato es "proporcionar al alumno formación, madurez intelectual y humana, conocimientos y habilidades que le permitan desarrollar funciones sociales e incorporarse a la vida activa con responsabilidad y competencia". Para ello deben desarrollar la formación lingüística y literaria, ya sea para acceder a la universidad, a los ciclos formativos de grado superior, o para incorporarse al mundo laboral.

Como en cualquier otro estadio educativo, la reflexión metalingüística del código solo tendrá sentido si contribuye a mejorar la expresión y la comprensión. En este punto, la formación de palabras cumple un papel fundamental. Para entender un texto científico - técnico o un poema es necesario conocer los mecanismos creativos de los que dispone la lengua, tanto en el nivel semántico como en el sintáctico. Solo conseguiremos coherencia y cohesión si dominamos la estructura interna de la lengua.

Llegados a este punto, y con la ayuda del desarrollo cognitivo de la adolescencia, debemos recalcar los siguientes principios propuestos por la semántica idiomática: primero, la palabra es una unidad compleja que posee un único significado, fruto de la unión de los significados de cada uno de sus constituyentes internos; segundo, dos o más palabras comparten el mismo significado invariante únicamente, si comparten el mismo lexema; tercero, la única forma coherente de estructurar el léxico de una lengua es por medio de las familias de palabras; y, por último, un significado puede generar infinitos sentidos contextuales (denotación - connotación).

El valor textual de las unidades debe tener como punto de partida la significación invariante que nos proporciona la raíz o el lexema. A este lexema se le unen otros significados (prefijos y sufijos), convirtiendo una simple palabra en un texto. Una vez que hayamos explicado todos estos significados y nos aproximemos al significado único de la voz, podremos pasar al campo de la variación: ¿qué sentido ha desarrollado la voz? ¿En qué momento? ¿Ese nuevo sentido es fruto de un procedimiento metafórico o metonímico? ¿Qué connotación tiene en el texto? ¿Por 
qué el autor utilizó esa unidad y no otra? Si somos capaces de resolver estos enigmas, seremos capaces de comentar lingüísticamente el texto.

En este nivel educativo los artículos de opinión son aptos para trasladar la reflexión metalingüística a la realidad. Así, en el siguiente artículo de El País, podríamos reflexionar por qué Obama "entra en juego" y no "entra en acción". ¿Qué significado aporta "juego" al texto? Si hay juego de por medio, sabemos de antemano que hay dos posibles finales: ganar o perder. Por ello, en este caso Obama "ha empezado a jugar sus cartas" a la espera de un resultado.

\section{Obama entra en juego}

Las primeras decisiones sobre Palestina revelan que EE UU quiere asumir un papel más activo

La extrema prudencia del presidente norteamericano Barack Obama en sus contadas declaraciones sobre el conflicto de Palestina muestra hasta qué punto éste preocupa a Washington; pero también la celeridad con que la Casa Blanca ha empezado a jugar sus cartas con el envío de George Mitchell el pasado fin de semana a la zona revela cómo, a diferencia de la Administración de George Bush, sí hay decisión de tomar el toro por los cuernos. Una cautela similar en Israel, que celebrará elecciones legislativas el próximo día 10, revela, en cambio, la aprensión con que el Gobierno encara una nueva ronda diplomática con un presidente que tiene parientes musulmanes y ha declarado a medios árabes que aspira a la mejor relación con el mundo islámico.

El País, 01/02/2009

El artículo nos conducirá a analizar el significado de voces destacables como los adjetivos "extrema" y "contadas", o el verbo "encarar". El significado proporcionará el valor textual de la unidad, y a partir de ahí podemos llegar sin ningún problema a extraer las connotaciones que puedan tener en todo el entramado textual.

También podemos recurrir a las letras musicales para amenizar el estudio de la formación de palabras. En un posible ejercicio podríamos ofrecer a los alumnos que localicen en las canciones palabras derivadas y compuestas, explicando a continuación su significado; o bien, les proponemos nosotros mismos las voces que deben estudiar (Ejercicio 10). 
Ejercicio 10. Comenta cómo se han formado las palabras subrayadas en esta canción de Estopa:

\section{“HEMICRANEAL” (Allenrok, Estopa)}

Deja que la lluvia acaricie tus párpados y que la humedad se clave en tu piel, deja que esta noche tus pies anden $\underline{\text { descalzos }}$, no los pares si empiezan a correr.

Deja que el deseo por una vez se cumpla, deja que el silencio te susurre otra vez, deja que tu ausencia en una depresión se hund deja que el niño que llevas dentro vuelva a nac

Deja que la gente pase a ambos lados sin tocar1 y que el neón de la noche se clave en tu sien, deja que la duda que hay en tu mente no pregu y que no se clave, que ni siquiera hable y que se muera solo por esta vez.

\author{
Deja que los coches te salpiquen cuando pasen, \\ que mojen tu risa, con tu puta prisa antes de morder \\ esa manzana envenenada por un jodido martes, \\ que se pregunten qué haces en la calle, \\ que no se den cuenta de ese detalle. \\ Que esto es un paseo como los de antes, \\ el que nadie se busca, nadie quiere encontrarse, \\ que todo se vuelca en un vaso vacío, \\ que no hay más nostalgia que la de perderse. \\ Si duele un recuerdo, te cura el olvido, \\ si duele la cabeza, con Hemicraneal vale. \\ si buscas ayuda, chungo, esta noche estoy solo conmigo.
}

No solo será un ejercicio para trabajar la segmentación de las palabras (por ejemplo, des- + calz- $+-o+-s$ ), sino que trabajaremos también el origen de la voz, su evolución, los posibles cambios semánticos, sus campos de uso, su pertenencia a una familia de palabras, y los miembros de esta. La curiosidad del alumno puede llevar a preguntar cómo se ha formado, por ejemplo, el título del último disco de Estopa, es decir, la palabra "allenrok". Aunque no es una palabra lexicalizada en español, como estudiantes de la lengua debemos encontrar qué recurso creativo ha hecho posible su formación. En este caso es el orden inverso de las letras de la palabra Cornella, localidad natal de los componentes de Estopa, con un ligero cambio de la grafía $(<\mathrm{k}>$ en lugar de $\langle\mathrm{c}>$ ), hecho que no supone ningún problema ya que ambas grafías representarían el fonema oclusivo velar sordo. Estas pequeñas explicaciones permiten demostrar que toda palabra remite a una determinada estructura.

Los alumnos de Bachillerato deben de ser capaces de aproximarse al significado de los distintos morfemas. Si los alumnos cursan el Bachillerato de humanidades con las asignaturas de latín y griego, podrán trabajar con mayor facilidad el origen y la evolución de las palabras españolas (tanto las palabras cultas como las palabras patrimoniales). Podrán practicar, por tanto, las familias de palabras en latín, observando las correspondencias en español (véase la Imagen 9). 


\begin{tabular}{|l|c|c|c|}
\hline \multirow{2}{*}{ Prefijos } & \multicolumn{3}{|c|}{ Verbos } \\
\cline { 2 - 4 } & Sequor & Tendo & Solvo \\
\hline Ad & $\mathrm{x}$ & $\mathrm{x}$ & \\
\hline Cum & $\mathrm{x}$ & $\mathrm{x}$ & $\mathrm{x}$ \\
\hline$E x$ & $\mathrm{x}$ & $\mathrm{x}$ & $\mathrm{x}$ \\
\hline$I n$ & $\mathrm{x}$ & $\mathrm{x}$ & \\
\hline$O b$ & $\mathrm{x}$ & $\mathrm{x}$ & $\mathrm{x}$ \\
\hline$P e r$ & $\mathrm{x}$ & $\mathrm{x}$ & \\
\hline$P r o$ & $\mathrm{x}$ & $\mathrm{x}$ & $\mathrm{x}$ \\
\hline Sub & & $\mathrm{x}$ & $\mathrm{x}$ \\
\hline$R e$ & $\mathrm{n}$ & $\mathrm{x}$ \\
\hline Dis & &
\end{tabular}

Imagen 9. Estudio de la familia de palabras de tres verbos latinos a partir de prefijos

En este tipo de ejercicios podemos observar la productividad de muchos lexemas y morfemas en latín, y por consiguiente, su productividad en las lenguas romances, y en concreto en español:

$\begin{array}{lllll}\text { Cum } & + & \text { sequor } & > & \text { conseguir } \\ \mathrm{Ex} & + & \text { sequor } & > & * \text { exequiar (> exequias) } \\ \mathrm{Ob}+ & \text { sequor } & > & \text { obsequiar } \\ \mathrm{Per}+ & \text { sequor } & > & \text { perseguir } \\ \text { Pro }+ & \text { sequor } & > & \text { proseguir } \\ \mathrm{Sub}+ & \text { sequor } & > & * \text { subseguir }(>\text { subsiguiente) }\end{array}$

Pero, ¿cómo conduciremos al alumno por este nivel abstracto de significación? Teniendo como modelo la bibliografía existente ${ }^{8}$, propondremos a los alumnos unidades que contrastan por el significado de sus morfemas. Por ejemplo:

En gato / gata, palo /pala o cubo/ cuba, aunque tradicionalmente la lingüística ha considerado a los morfemas $-o /-a$ como flexivos por incorporarse al final de la palabra, siguen siendo morfemas derivativos. Estos sufijos no significan invariablemente "sexo masculino" y "sexo femenino" respectivamente, ya que esto solo se produce cuando denotan seres vivos, y no en todos los casos. Podríamos

${ }^{8}$ Para el estudio de los prefijos y sufijos se debe consultar la obra Apuntes para una gramática del español de base semántica, tanto el tomo dedicado a la morfología como el dedicado a la sintaxis, publicados por Morera (1999 y 2000), y La complementación morfológica en español (Morera, 2005); para el estudio de la familia de palabras se debe consultar la familia de palabras part- propuesta por García Padrón (2004, 2005 y 2006); las familias de palabras fer-, pas-, buf-, y punt- propuestas por Morera (2007), y la familia de palabras seg- propuesta por Jorge Rodríguez (2010). 
definir el morfema -o como 'cuantificación genérica de la significación de la raíz concentrada', frente al morfema -a que sería 'cuantificación genérica de la significación de la raíz expandida'. Esto es solo una aproximación al significado, es una metáfora del posible significado. ¿Por qué hablamos de concentración vs. expansión? El sufijo -o es más abarcador que el sufijo -a, porque concentra la significación de la raíz, lo que le permite, entre otras cosas, nombrar al género masculino y al femenino.

En realidad, lo que el alumno debe entender es que cada sufijo tiene un significado. Así, los sufijos -ito, -illo, -ete pueden confluir en el nivel contextual con el valor de diminutivo, pero no es lo mismo gordito, que gordillo o gordete. En gordillo la significación de la raíz se manifiesta con más fuerza que en gordito, siendo por ello más peyorativo, y en gordete esa intensidad disminuye mucho más, llegando a desvanecerse los límites de la significación gordo. En el caso de los sufijos aumentativos podemos encontrar una diferencia semejante. Por ejemplo, entre grandón y grandote hay una diferencia de superación de la significación. En el primer caso se supera la significación de grande de forma indefinida, frente a grandote en la que la significación se ve simplemente desbordada. En una escala cuantificadora podríamos decir que grandón es muy grande, frente al grandote que es un poco grande. Otro tipo de expansión de la significación se produce con el sufijo - al o su variante formal -ar, con el que la significación de la base se expande en todas las direcciones. En la palabra pinar, la significación pino se difunde por todas partes, lo que le permite denotar 'colectividad'.

En el sufijo -ura no hay concentración de la significación como en los aumentativos y en los diminutivos, sino abstracción. Entre lectura y lector hay una diferencia importante: en el primer caso se abstrae la significación de leer con pasividad, frente al lector que es una abstracción activa (por ello puede designar a la persona que lee).

En amado / amante, cantado /cantante, o pasado /pasante, la acción del verbo del primer miembro de la dicotomía se presenta acabada, se presenta como si estuviera situada en el pasado, de ahí que tenga cierto matiz pasivo. Frente a esto, el morfema nte presenta la acción en desarrollo, sin acabar. Esto es lo que distingue al participio de pasado del participio de presente.

Comparando voces en las que contrasten en el mismo lugar los distintos morfemas podremos entresacar el significado invariante de cada sufijo o prefijo (véase la Imagen 10). No olvidemos que en todo momento hay que abordar el estudio de la variación denotativa, pues sin esta la significación no tendría existencia. Un sufijo como -ito no solo denota empequeñecimiento (librito), sino también cría (perrito), o persona joven (Anita). Además se usa para atenuar la intensidad del elemento nuclear (el fueguito tiene menos intensidad que el fuego), para marcar el respeto hacia personas mayores en las islas orientales del archipiélago canario (Juanito), etc. 


\begin{tabular}{|c|c|c|}
\hline$\underline{\text { Sentidos }}$ & Sufijos nominales & Significado \\
\hline $\begin{array}{l}\text { Género } \\
\text { masculino }\end{array}$ & $-o /-e$ & $\begin{array}{l}\text { 'Cuantificación genérica de la significación de la } \\
\text { raíz concentrada' }\end{array}$ \\
\hline Género femenino & $-a$ & $\begin{array}{l}\text { 'Cuantificación genérica de la significación de la } \\
\text { raíz expandida' }\end{array}$ \\
\hline \multirow[t]{3}{*}{ Diminutivo } & -ito, -ita & $\begin{array}{l}\text { 'Cuantificación definida de la significación de la } \\
\text { raíz que apenas alcanza el límite' }\end{array}$ \\
\hline & -illo & $\begin{array}{l}\text { 'Cuantificación no definida - no intensa de la } \\
\text { significación de la raíz que apenas llega al límite' }\end{array}$ \\
\hline & -ete & $\begin{array}{l}\text { 'Cuantificación difusa de la significación de la } \\
\text { raíz sin superación del límite' }\end{array}$ \\
\hline \multirow[t]{2}{*}{ Aumentativo } & -ón & $\begin{array}{l}\text { 'Cuantificación no definida de la significación } \\
\text { de la raíz con superación del límite' }\end{array}$ \\
\hline & -ote & $\begin{array}{l}\text { 'Cuantificación definida de la significación de la } \\
\text { raíz con superación del límite' }\end{array}$ \\
\hline $\begin{array}{l}\text { Formación de } \\
\text { sustantivos } \\
\text { abstractos }\end{array}$ & -ura & $\begin{array}{l}\text { 'Abstracción pasiva de la significación de la } \\
\text { raíz' }\end{array}$ \\
\hline \multirow[t]{2}{*}{ Conjunto de ... } & $-a b /-a r$ & $\begin{array}{l}\text { 'Expansión de la significación de la raíz en todas } \\
\text { las direcciones' }\end{array}$ \\
\hline & Sufijos verbales & \\
\hline Participio & $-d o$ & $\begin{array}{c}\text { 'Cuantificación verbal que presenta la } \\
\text { significación de la raíz terminada' }\end{array}$ \\
\hline Agente & -nte & $\begin{array}{l}\text { 'Cuantificación verbal que presenta la } \\
\text { significación de la raíz en desarrollo activo' }\end{array}$ \\
\hline
\end{tabular}

Imagen 10. Acercamiento al significado de algunos de los principales sufijos ${ }^{9}$

La misión del profesor es completar en la medida de lo posible, según las habilidades que hayan alcanzado los alumnos, el cuadro con todos los elementos compositivos y derivativos posibles en español. Junto al significado invariante de estas unidades deben aparecer los sentidos contextuales más importantes, sus diferencias estilísticas, sus restricciones de uso y su valor textual.

\section{CONCLUSIONES}

La enseñanza del léxico nos plantea un problema didáctico serio ya que se nos abren múltiples vías de tratamiento. La labor del profesorado es sopesar las ventajas e inconvenientes de cada uno de los métodos científicos que están a nuestro alcance,

9 Es imprescindible para completar la tabla consultar la obra La complementación morfológica en español (Morera, 2005). 
para evitar que se cree en el alumno una confusión terminológica. Del estudio que hemos realizado podríamos extraer las siguientes conclusiones:

Primero, el ser humano está capacitado genéticamente para interiorizar la lengua, por lo que su desarrollo dependerá de las condiciones particulares de cada sujeto y de la estimulación que reciba del exterior.

Segundo, el profesor de lengua es el encargado de guiar la estructuración del léxico del alumno, por lo que debe tener en cuenta cómo enseñará el vocabulario. Si bien tenemos tres modelos de análisis del léxico (perspectiva de la lexicografía tradicional, perspectiva de los campos semánticos y perspectiva de la familia de palabras), desde nuestro punto de vista, solo el modelo de las familias de palabras nos proporciona una estructuración coherente, que se apoya en principios estrictamente lingüísticos.

Tercero, la concepción de las familias de palabras nos conduce a una corrección de los conceptos tradicionales de significado y de formación de palabras. Así, el significado es una intuición semántica que carece de referente, es decir, no es conceptual, es inefable e intraducible intralingüística, interlingüística y extralingüísticamente. El significado de las palabras es la suma de distintos procedimientos semánticos formales (significación primaria, significación categorial, significación morfológica y significación sintáctica).

Cuarto, la capacidad designativa del significado es infinita, puesto que a partir de un único significado se pueden generar múltiples usos contextuales.

Quinto, y según lo dicho, una familia de palabras estaría formada por todas las unidades que comparten una misma significación primaria (formalizada por medio de un significante o raíz), ya sean variaciones categoriales, morfológicas o sintácticas, unido al campo de uso que ha desarrollado cada voz.

Sexto, el desarrollo de esta teoría en la enseñanza solo es posible si se adecuan los contenidos según los objetivos que nos marquemos en cada etapa educativa y si se evitan las incongruencias terminológicas existentes hasta el momento. Aunque en la actualidad el método de los campos semánticos ha ganado terreno, hemos demostrado que no es el más adecuado, ya que su apego a la realidad conduce inevitablemente al niño a un léxico deficitario y poco estructurado. Los campos semánticos serán útiles en los primeros estadios del aprendizaje, ya que de esta forma presentamos la realidad al hablante. Sin embargo, pronto el niño se despegará de la realidad y comenzará con abstracciones, hecho que favorece el acercamiento al significado. La evolución genética del alumno es la mejor guía didáctica para el profesor.

Los distintos modelos de ejercicios que hemos propuestos según las etapas educativas (Educación Infantil, Educación Primaria, Educación Secundaria Obligatoria y el Bachillerato), no son más que una muestra de las múltiples vías que se nos abren a la hora de abordar el estudio del léxico según la teoría de las familias de palabras. El alumno pasará desde la derivación más sencilla hasta la compleja composición, buscando las similitudes y diferencias entre las unidades, y abstrayendo la esencia de cada una de ellas. De esta forma desarrolla una de las competencias básicas: la autonomía personal o el autoaprendizaje. 
En definitiva, la enseñanza del léxico no es un problema que se pueda resolver en unas cuantas líneas. Con este estudio hemos tratado de ilustrar de manera clara y ejemplificadora los distintos modelos lingüísticos que estructuran el léxico para demostrar que solo partiendo del análisis de las familias de palabras podremos comprender el verdadero funcionamiento de la lengua en cada uno de los distintos niveles educativos.

\section{REFERENCIAS BIBLIOGRÁFICAS}

AGUADO, Gerardo (2000): El desarrollo del lenguaje de 0 a 3 años, Madrid, editorial CEPE.

ALVAR EZQUERRA, Manuel (2003): La enseñanza del léxico y el uso del diccionario, Madrid, editorial Arco Libros.

BIGAS, Monserrat / CORREIG, Monserrat (eds) (2001): Didáctica de la lengua en la educación infantil, Madrid, Editorial Síntesis.

CASARES, Julio (1992): Introducción a la lexicografía moderna, Madrid, CSIC.

GARCÍA PADRÓN, Dolores (1998): "Hacia un modelo explicativo de la organización léxico - semántica en las lenguas", en Teoría de campo y semántica léxica / Théorie des champs et sémantique lexicale, WOTJAK, G. (ed.), Frankfurt am Main, Peter Lang, pp. 65-85.

GARCÍA PADRÓN, Dolores (2004): "Significado y variación de la raíz PART- en español", en Revista española de lingüistica RSEL, 34, 2, pp. 455-480.

GARCÍA PADRÓN, Dolores (2005): "Variaciones gramaticales y denotativas de la familia de palabras PART- en su manifestación categorial verbal", en Algunos problemas especificos de la descripción sintáctico - semántica, CUARTERO, J. y G. WOTJAK (eds.), Berlín, Frank y Timme Verlag, pp. 145-158.

GARCÍA PADRÓN, Dolores (2006): "La manifestación categorial sustantiva de PART- en español", en Actas del VI Congreso de Lingüística General.

GIMÉNEZ DE LA PEÑA, Almudena (2003): Manual de prácticas de psicología del lenguaje, Málaga, Ediciones Aljibe.

JORGE RODRÍGUEZ, Nicolás A. (2010): “Aproximación al estudio de la familia de palabras seg-: variación morfológica, sintáctica y denotativa", en Tendencias en lingüistica general y aplicada, GARCÍA PADRÓN, D. y FUMERO PÉREZ, María del Carmen (eds.), Frankfurt am Main, Peter Lang, pp. 145 - 153.

MORERA PÉREZ, Marcial (1994): "Hacia un delimitación de los conceptos de gramática y lexicología", en Revista de Filología de la Universidad de La Laguna, núm. 13, pp. 277-289.

MORERA PÉREZ, Marcial (1998): "La naturaleza del significado léxico", en Teoría de campo y semántica léxica / Théorie des champs et sémantique lexicale WOTJAK, Gerd (ed.), Frankfurt am Main, Peter Lang, pp. 127 - 156.

MORERA PEREZ, Marcial (1999): Apuntes para una gramática del español de base semántica. Morfología, Puerto del Rosario, Servicio de Publicaciones del Excmo. Cabildo de Fuerteventura. 
MORERA PÉREZ, Marcial (2000): Apuntes para una gramática del español de base semántica. Sintaxis, Puerto del Rosario, Servicio de Publicaciones del Excmo. Cabildo de Fuerteventura.

MORERA PÉREZ, Marcial (2000 - 2001): "Familia de palabras vs. campo semántico. Los casos particulares de las familias punt-, punz-y pinch-", en Revista de Lexicografia, VIII.

MORERA PÉREZ, Marcial (2005): La complementación morfológica en español. Ensayo de interpretación semántica, Frankfurt am Main, Peter Lang.

MORERA PÉREZ, Marcial (2007): La gramática del léxico español, Badajoz, Editorial Abecedario.

NARBONA, Juan / CHEVRIE - MULLER, Claude (eds.) (2001): El lenguaje del niño. Desarrollo normal, evaluación y trastornos, Barcelona, Masson.

OLLER, D. Kimbrough (1980): "The emergence of the sounds of speech in infancy", en Child Phonology, vol. 1. Production, YENI-KOMSHIAM, G., KAVANAGH, JF., FERGUSON, CA. (eds.), Nueva York, Academic Press.

OLLER, D. Kimbrough / LYNCH, Michael P. (1993): "Infant vocalization and innovation in infraphonology: toward a broader theory of development and disorders", en Phonological development, FERGUSSON, C., MENN, L., STOELGAMMON, C. (eds), Parkton MD, York Press.

ORTEGA OJEDA, Gonzalo (1996): La enseñanza de la lengua española en Canarias, Tenerife, Instituto de Estudios Canarios.

PITA GHERARDI, Esther / ARRIBAS, Jesús (1991): Estructuras básicas de la comunicación oral, Madrid, Editorial CEPE.

TRUJILlO, Ramón (1976): Elementos de semántica lingüistica, Madrid, editorial Cátedra.

TRUJILLO, Ramón (1988): Introducción a la semántica española, Madrid, editorial Arco Libros.

TRUJILLO, Ramón (1996): Principios de semántica textual, Madrid, editorial Arco Libros.

TRUJILLO, Ramón (1998): "Para una discusión del concepto de campo semántico", en Teoría de campo y semántica léxica / Théorie des champs et sémantique lexicale, WOTJAK, G. (ed.), Frankfurt am Main, Peter Lang, pp. 87- 125.

VARELA ORTEGA, Soledad (2005): Morfología lexica: la formación de palabras, Madrid, editorial Gredos.

VINTER, Shirley (1985): L'emergence du langage de l'enfant deficient auditif: Des premiers sons aux premiers mots, París, Masson, 1994. 